Transfers within a three generations family: when the rotten kids turn into altruistic parents

Helmuth Cremer and Kerstin Roeder 


\title{
Transfers within a three generations family: when the rotten kids turn into altruistic parents*
}

\author{
Helmuth Cremer ${ }^{\dagger}$ \\ Toulouse School of Economics
}

\author{
Kerstin Roeder ${ }^{\ddagger}$ \\ LMU, Munich
}

May 2014

\begin{abstract}
We study exchanges between three overlapping generations with non-dynastic altruism. The middleaged choose informal care provided to their parents and education expenditures for their children. The young enjoy their education, while the old may leave a bequest to their children. Within each period the three generations play a "game" inspired by Becker's $(1974,1991)$ rotten kids framework, with the added features that the rotten kids turn into the altruistic parent in the next period and that parents invest in the education of their children. We show that Becker's rotten kids theorem holds for the single period game in that informal aid is set according to an efficient rule. However, education is distorted upwards. In the stationary equilibrium the levels of both transfers are inefficient: education is too large and informal aid is too low.
\end{abstract}

Keywords: rotten kids, altruism, education, long-term care, subgame perfect equilibrium, overlapping generations

JEL-Classification: Dl, D7, D9

\footnotetext{
*Financial support from the Chaire "Marché des risques et creation de valeur" of the FdR/SCOR is gratefully acknowledged. We thank Emmanuel Thibault for his very helpful comments and suggestions.

${ }^{\dagger}$ Corresponding Author, Toulouse School of Economics, 21 Allée de Brienne, 31015 Toulouse, France. Email: helmuth.cremer@tse-fr.eu, Phone: +33 (0)5 61128606.

${ }^{\ddagger}$ University of Munich, Department of Economics, Ludwigstr. 28, 80539 Munich, Germany. Email: kerstin.roeder@lrz.uni-muenchen.de, Phone: +49 (0)892180 1392, Fax: +49 (0)892180 3128.
} 


\section{Introduction}

Understanding intergenerational transfers within the family is a crucial ingredient for the design of various policies like education and long-term care. This paper studies intergenerational exchanges in an overlapping generation (OLG) framework with three generations: the young, the middleaged (parents) and the old (grandparents). The parents choose two transfers: (i) informal care provided to their parents, and (ii) education expenditures for their children. The young enjoy their education while the old may leave a bequest to their children. Individuals are altruistic but in a non-dynastic way; altruism is limited to the following generation. Within each period the three generations play a "game" inspired by Becker's $(1974,1991)$ rotten kids framework, with the added features that the rotten kids turn into the altruistic parent in the next period and that parents invest in the education of their children. We study the subgame perfect equilibrium of the single-period game and then determine the stationary equilibrium of the multi-period setting.

Our results corroborate Becker's "rotten kids theorem" but only to a rather limited extent. First, his efficiency result obtains only in the single-period game and only for caregiving services but not for education. Specifically, aid is set according to an efficient tradeoff, while there is an upward distortion in education spending. Second, the stationary equilibrium levels of both aid and education are inefficient. Investments in education are too high and this "spills over" to aid, the level of which is too low. This is because excessive education, by boosting the wage rate, increases the opportunity cost of aid. ${ }^{1}$

There exists an extensive literature which studies education in an OLG model, but these papers concentrate on very different issues like inequality, growth or the role of public education. ${ }^{2}$ The predecessors to our paper which also focus on intergenerational transfers to the young and old, on the other hand, do not consider altruism. For instance Cremer et al. (1992) show that selfish parents underinvest in the education of their children (even when they can commit to a strategic bequest rule). In their model the parent's incentives to invest in their offspring's education are solely driven by the surplus they can extract from an attention-for-bequest game. In a similar vein Rangel (2000) and Boldrin and Montes (2005) consider voluntary exchanges between selfish generations.

\footnotetext{
${ }^{1}$ It is by now well known that Becker's theorem applies only under rather stringent conditions; see Bergstrom (1989). However, these conditions hold in the one period version of our model; the failures we identify are of a completely different nature and due to the OLG framework.

${ }^{2}$ See Glomm, Ravikumar and Schiopu (2011) and Oded (2011) for recent overviews of this literature.
} 
They show that providing education to the young is generally not sustainable unless it is bundled with sufficiently large transfers (like a PAYGO pension scheme) to the old.

\section{The model}

Consider an OLG framework with three generations. Every period $t$ a new generation is born and lives for three periods. The agent is a child (superscript ' $c$ ') in the first period, a parent (superscript ' $p$ ') in the second period and a grandparent (superscript ' $g$ ') in the third period. Each generation consists of a single individual and is perfectly altruistic towards the next generation. We assume that altruism is non-dynastic: parents are altruistic only towards their own children but not towards their grandchildren. Every period the parent decides how much to save $s_{t}$, how much care $a_{t}$ to provide to the old generation and how much education $e_{t}$ to invest in the young generation. We assume that the price for education is one and that care costs time of which the total amount is again normalized to one. Grandparents are retired and have a monetary value $h\left(a_{t}\right)$ (with $h^{\prime}>0$ and $\left.h^{\prime \prime}<0\right)$ of the care they receive from their children. The residual time $1-a_{t}$ is spend on the labor market for which the parent receives a wage rate $w\left(e_{t-1}\right)$. Their wage rate increases in the education they got from their parents (the current grandparents) implying $w^{\prime}>0$. The current old choose the bequest $b_{t} \geq 0$ to leave to their children (the current parents). The young simply enjoy their education and have no other decision to make. The utility functions of the three generations in period $t$ are given by

$$
\begin{aligned}
U_{t}^{g}= & u\left(s_{t-1}+h\left(a_{t}\right)-b_{t}\right)+u\left(\left(1-a_{t}\right) w\left(e_{t-1}\right)-e_{t}+b_{t}-s_{t}\right)+u\left(s_{t}+h\left(a_{t+1}\right)-b_{t+1}\right), \\
U_{t}^{p}= & u\left(\left(1-a_{t}\right) w\left(e_{t-1}\right)-e_{t}+b_{t}-s_{t}\right)+u\left(s_{t}+h\left(a_{t+1}\right)-b_{t+1}\right) \\
& +u\left(e_{t}\right)+u\left(\left(1-a_{t+1}\right) w\left(e_{t}\right)-e_{t+1}+b_{t+1}-s_{t+1}\right)+u\left(s_{t+1}+h\left(a_{t+2}\right)-b_{t+2}\right), \quad(2) \\
U_{t}^{c}= & u\left(e_{t}\right)+u\left(\left(1-a_{t+1}\right) w\left(e_{t}\right)-e_{t+1}+b_{t+1}-s_{t+1}\right)+u\left(s_{t+1}+h\left(a_{t+2}\right)-b_{t+2}\right) \\
& +u\left(e_{t+1}\right)+u\left(\left(1-a_{t+2}\right) w\left(e_{t+1}\right)-e_{t+2}+b_{t+2}-s_{t+2}\right)+u\left(s_{t+2}+h\left(a_{t+3}\right)-b_{t+3}\right),
\end{aligned}
$$

with $u^{\prime}>0$ and $u^{\prime \prime}<0$. In the following we denote consumption levels in period $t$ for a parent as $d_{t}$ and for a grandparent as $m_{t}$. 


\section{Optimal allocation}

As often in a dynamic setting, we define the optimum as the allocation that maximizes the lifetime utility of an individual who treats his children and his parents as he would have liked to be treated himself when a child or when a parent (see, e.g., Cremer et $a l .$, 1992). Note that the individual successively takes the role of $c, p$, and then $g$. We count only the own utility, laundering out the altruistic terms. This yields the following optimization problem

$$
\max _{s, b, a, e} W=u(e)+u((1-a) w(e)-e+b-s)+u(s+h(a)-b) .
$$

To ensure an interior solution we assume that $W$ is concave. The first order conditions (FOCs) are given by

$$
\begin{aligned}
& \frac{\partial W}{\partial s}=-u^{\prime}(d)+u^{\prime}(m)=0 \\
& \frac{\partial W}{\partial b}=-u^{\prime}(m)+u^{\prime}(d)=0 \\
& \frac{\partial W}{\partial a}=u^{\prime}(m) h^{\prime}(a)-u^{\prime}(d) w(e)=0 \quad \Rightarrow \quad h^{\prime}(a)=w(e), \\
& \frac{\partial W}{\partial e}=-u^{\prime}(d)+u^{\prime}(e)+u^{\prime}(d)(1-a) w^{\prime}(e)=0 .
\end{aligned}
$$

Note that only $b-s$ (the net transfer) is determined. Let $a^{*}, e^{*}, d^{*}$ and $m^{*}$ denote the solution to equations (5)-(8).

\section{Equilibrium}

In each period $t$, parent and grandparent play the following three stage game. First, the parent chooses $a_{t}$, the time devoted to aid their parent and the amount of money to spend on the education of their child, $e_{t}$. Second, the grandparent decides how much to leave as a bequest, $b_{t}$. Finally, the parent chooses how much to save for old age, $s_{t}$. Children receive education but do not make any decision. However, their utility affects $p$ and $g$ 's decisions through the altruistic terms in their utility. While playing this game, $p$ and $g$ consider all past and future decisions made by other players as given (see, e.g., Veall, 1986). In each period $t$, the variables $\left(a_{t}, e_{t}, b_{t}, s_{t}\right)$ are determined by the subgame perfect equilibrium of this game. Observe that the timing of this game along with the requirement for subgame perfection implies that grandparents cannot commit to some 
bequest rule which "rewards" or pays the caregivers. This rules out a strategic bequest type solution. A stationary equilibrium denoted $(\bar{a}, \bar{e}, \bar{b}, \bar{s})$ is achieved when the solution remains constant over time. We determine the subgame perfect equilibrium in period $t$ and then characterize the stationary equilibrium.

\subsection{Period $t$}

As usual the game is solved by backward induction.

\subsubsection{Stage 3: savings}

When deciding how much to save parents solve the following problem

$$
\begin{aligned}
\max _{s_{t}} U_{t}^{p}= & u\left(\left(1-a_{t}\right) w\left(e_{t-1}\right)-e_{t}+b_{t}-s_{t}\right)+u\left(s_{t}+h\left(a_{t+1}\right)-b_{t+1}\right) \\
& +u\left(e_{t}\right)+u\left(\left(1-a_{t+1}\right) w\left(e_{t}\right)-e_{t+1}+b_{t+1}-s_{t+1}\right)+u\left(s_{t+1}+h\left(a_{t+2}\right)-b_{t+2}\right) .
\end{aligned}
$$

Observe that all other variables set in period $t$ are by now given. Similarly all past and future decisions made by other players are considered as given. ${ }^{3}$ Optimal savings are determined by the following FOC

$$
-u^{\prime}\left(d_{t}\right)+u^{\prime}\left(m_{t+1}\right)=0
$$

Savings $s_{t}^{e} \equiv s_{t}\left(b_{t}, a_{t}, e_{t}\right)$ are chosen to (perfectly) smooth consumption over time. Comparative statics with respect to $b_{t}, a_{t}$ and $e_{t}$ are given by

$$
\begin{aligned}
& \frac{\partial s_{t}^{e}}{\partial b_{t}}=\frac{u^{\prime \prime}\left(d_{t}\right)}{u^{\prime \prime}\left(d_{t}\right)+u^{\prime \prime}\left(m_{t+1}\right)}=\frac{1}{2}>0, \\
& \frac{\partial s_{t}^{e}}{\partial a_{t}}=\frac{-u^{\prime \prime}\left(d_{t}\right) w\left(e_{t-1}\right)}{u^{\prime \prime}\left(d_{t}\right)+u^{\prime \prime}\left(m_{t+1}\right)}=-\frac{w\left(e_{t-1}\right)}{2}<0, \\
& \frac{\partial s_{t}^{e}}{\partial e_{t}}=\frac{-u^{\prime \prime}\left(d_{t}\right)}{u^{\prime \prime}\left(d_{t}\right)+u^{\prime \prime}\left(m_{t+1}\right)}=-\frac{1}{2}<0 .
\end{aligned}
$$

In words, a higher inheritance increases savings by half of the additional wealth. Higher aid reduces savings by half of the income loss that comes along with the provision of care. Finally, higher education investments in the young reduce savings by half the amount invested.

\footnotetext{
${ }^{3}$ We do not assume that $b_{t+1}$ is considered as given. Parents may realize that their current savings affect the bequest they will leave next period. However, because of the envelope theorem, this has no first-order effect on $U_{t}^{p}$.
} 


\subsubsection{Stage 2: bequests}

In the second stage the old generation chooses $b_{t}$ to maximize

$$
\begin{aligned}
\max _{b_{t}} U_{t}^{g}= & u\left(s_{t-1}+h\left(a_{t}\right)-b_{t}\right)+u\left(\left(1-a_{t}\right) w\left(e_{t-1}\right)-e_{t}+b_{t}-s_{t}^{e}\right) \\
& +u\left(s_{t}^{e}+h\left(a_{t+1}\right)-b_{t+1}\right) .
\end{aligned}
$$

When determining the optimal bequests the grandparent takes into consideration its effect on their offspring's savings, that is

$$
-u^{\prime}\left(m_{t}\right)+u^{\prime}\left(d_{t}\right)\left[1-\frac{\partial s_{t}^{e}}{\partial b_{t}}\right]+u^{\prime}\left(m_{t+1}\right) \frac{\partial s_{t}^{e}}{\partial b_{t}}=0 .
$$

Using equations (10) and (11), the above equation can be rewritten as

$$
-u^{\prime}\left(m_{t}\right)+u^{\prime}\left(d_{t}\right)=0
$$

The bequest $b_{t}^{e} \equiv b\left(a_{t}, e_{t}\right)$ is chosen so as to equalize consumption levels of the grandparent and the parent. Taking into consideration (12) and (13) the comparative static effects with respect to $a_{t}$ and $e_{t}$ are given by

$$
\begin{aligned}
\frac{\partial b_{t}^{e}}{\partial a_{t}} & =\frac{u^{\prime \prime}\left(m_{t}\right) h^{\prime}\left(a_{t}\right)+u^{\prime \prime}\left(d_{t}\right)\left[w\left(e_{t-1}\right)+\frac{\partial s_{t}^{e}}{\partial a_{t}}\right]}{u^{\prime \prime}\left(m_{t}\right)+u^{\prime \prime}\left(d_{t}\right)\left[1-\frac{\partial s_{t}^{e}}{\partial b_{t}}\right]}=\frac{2 h^{\prime}\left(a_{t}\right)+w\left(e_{t-1}\right)}{3}>0 \\
\frac{\partial b_{t}^{e}}{\partial e_{t}} & =\frac{u^{\prime \prime}\left(d_{t}\right)\left[1+\frac{\partial s_{t}^{e}}{\partial e_{t}}\right]}{u^{\prime \prime}\left(m_{t}\right)+u^{\prime \prime}\left(d_{t}\right)\left[1-\frac{\partial s_{t}^{e}}{\partial b_{t}}\right]}=\frac{1}{3}>0 .
\end{aligned}
$$

Equation (16) shows that caregivers are in fact compensated for the aid they provide. However, $b_{t}^{e}$ cannot be arbitrarily chosen but it is given by the equilibrium of the second stage subgame. Grandparents only give as much as they find ex post (after aid is provided) optimal to bequeath given their altruism. This is in line with Becker's "rotten kids" mechanism; see Cremer and Roeder (2013) for a recent application to long-term care. Equation (17) is more unusual and due to the three generational setting we consider. Parents are in part compensated, by their own parents, for the expenditures on their child's education. This is because $e_{t}$ reduces their disposable income and thus increases their marginal utility of income. This, in turn, induces the altruistic grandparents to increase their bequest. 


\subsubsection{Stage 1: care and education}

In the first stage the parent chooses $a_{t}$ and $e_{t}$ to maximize

$$
\begin{aligned}
\max _{a_{t}, e_{t}} \quad U_{t}^{p}= & u\left(\left(1-a_{t}\right) w\left(e_{t-1}\right)-e_{t}+b_{t}^{*}-s_{t}^{*}\right)+u\left(s_{t}^{*}+h\left(a_{t+1}\right)-b_{t+1}\right)+u\left(e_{t}\right) \\
& +u\left(\left(1-a_{t+1}\right) w\left(e_{t}\right)-e_{t+1}+b_{t+1}-s_{t+1}\right)+u\left(s_{t+1}+h\left(a_{t+2}\right)-b_{t+2}\right) .
\end{aligned}
$$

The FOCs with respect to $a_{t}$ and $e_{t}$ are given by

$$
\begin{aligned}
& u^{\prime}\left(d_{t}\right)\left[-w\left(e_{t-1}\right)+\frac{\partial b_{t}^{*}}{\partial a_{t}}-\frac{\partial s_{t}^{*}}{\partial a_{t}}\right]+u^{\prime}\left(m_{t+1}\right) \frac{\partial s_{t}^{*}}{\partial a_{t}}=0, \\
& u^{\prime}\left(d_{t}\right)\left[-1+\frac{\partial b_{t}^{*}}{\partial e_{t}}-\frac{\partial s_{t}^{*}}{\partial e_{t}}\right]+u^{\prime}\left(m_{t+1}\right) \frac{\partial s_{t}^{*}}{\partial e_{t}}+u^{\prime}\left(e_{t}\right)+u^{\prime}\left(d_{t+1}\right)\left(1-a_{t+1}\right) w^{\prime}\left(e_{t}\right)=0 .
\end{aligned}
$$

With equations (12), (13), (16) and (17), the above FOCs can be rearranged as

$$
\begin{aligned}
& h^{\prime}\left(a_{t}\right)-w\left(e_{t-1}\right)=0, \\
& -\frac{2}{3} u^{\prime}\left(d_{t}\right)+u^{\prime}\left(e_{t}\right)+u^{\prime}\left(d_{t+1}\right)\left(1-a_{t+1}\right) w^{\prime}\left(e_{t}\right)=0 .
\end{aligned}
$$

Comparing these expressions with their counterparts in Section 3, equations (7) and (8), reveals that the equilibrium induces the efficient tradeoff for care but not for education. Specifically, equation (22) implies an upwards distortion in the level of education. This is because parents do not bear the full cost of their expenses; recall that $1 / 3$ is refunded via a higher bequest. Since they are altruistic they do however account for the full benefits of $e_{t}$.

\subsection{Stationary equilibrium}

Equations (10), (15), (21) and (22) show that the stationary equilibrium, $(\bar{a}, \bar{e}, \bar{b}, \bar{s})$, satisfies the following conditions

$$
\begin{aligned}
& u^{\prime}(\bar{d})-u^{\prime}(\bar{m})=0, \\
& h^{\prime}(\bar{a})-w(\bar{e})=0, \\
& -\frac{2}{3} u^{\prime}(\bar{d})+u^{\prime}(\bar{e})+u^{\prime}(\bar{d})(1-\bar{a}) w^{\prime}(\bar{e})=0,
\end{aligned}
$$

where $\bar{m}=\bar{s}+h(\bar{a})-\bar{b}$, and $\bar{d}=(1-\bar{a}) w(\bar{e})-\bar{e}+\bar{b}-\bar{s}$. Since (23) implies $\bar{m}=\bar{d}$, we have

$$
\bar{m}=\bar{d}=\frac{(1-\bar{a}) w(\bar{e})-\bar{e}+h(\bar{a})}{2} .
$$


The previous subsection has demonstrated that the period $t$ equilibrium involves an efficient tradeoff (rule) for $a_{t}$ but that the rule for $e_{t}$ implies an upward distortion. We now examine how these tradeoffs affect the equilibrium levels of $a$ and $e$ and how they compare to the optimal solution. Substituting from (23) and (24) into (25) we can express (25) solely as a function of $e$

$$
\phi(e)=u^{\prime}(e)+u^{\prime}(\bar{d}(e))\left\{[1-\bar{a}(e)] w^{\prime}(e)-\frac{2}{3}\right\},
$$

where

$$
\begin{aligned}
& \bar{a}(e)=h^{\prime-1}(w(e)), \\
& \bar{d}(e)=\frac{(1-\bar{a}(e)) w(e)-e+h(\bar{a}(e))}{2} .
\end{aligned}
$$

By definition we have $\phi(\bar{e})=0$. Since $\phi\left(e^{*}\right)>0$, we can conclude that if $\phi(e)$ is decreasing, we have $\bar{e}>e^{*}$. But, the expression for $\phi^{\prime}(e)$ is rather complicated and its sign is not obvious. So we take another path. By Substituting (5)-(7) into (8) we can express the latter equation solely as a function of $e$, this yields

$$
\phi^{*}(e)=u^{\prime}(e)+u^{\prime}\left(d^{*}(e)\right)\left\{\left[1-a^{*}(e)\right] w^{\prime}(e)-1\right\},
$$

where we have $a^{*}(e)=\bar{a}(e)$ and $d^{*}(e)=\bar{d}(e)$. By definition $e^{*}$ satisfies $\phi^{*}\left(e^{*}\right)=0$. Now, the concavity of $W$ (and the SOC for the optimal solution) imply that $\phi^{*}(e)$ is everywhere decreasing. ${ }^{4}$ Further observe that

$$
\phi(e)-\phi^{*}(e)=\frac{1}{3} u^{\prime}(d(e))>0 .
$$

In words, $\phi(e)$ is everywhere above $\phi^{*}(e)$ which in turn is decreasing. This immediately implies that $\bar{e}$, which is the solution to $\phi(e)=0$, is larger than $e^{*}$. This argument is illustrated in Figure 1 for $u(x)=\ln (x), w(e)=\sqrt{e}$ and $h(a)=\sqrt{a}^{5}$

To sum up, we have an equilibrium level of education, $\bar{e}$, that is larger than the optimal level $e^{*}$. Interestingly, this inefficiency "spills over" to the provision of aid. To see this,

\footnotetext{
${ }^{4}$ The detour via $\phi^{*}$ is necessary because we cannot sign $\phi^{\prime}$ (which is an equilibrium condition and not a FOC) from the SOC. On the other hand $\phi^{* \prime}$ is the SOC for the maximization of $W$ (reformulated to have $e$ as single decision variable).

${ }^{5}$ The figure also illustrates existence and uniqueness of the stationary equilibrium. Similar pictures arise for different parameter values. A thorough study of the conditions for existence and uniqueness would go beyond the scope of this note. From that perspective the illustration is useful because it shows that no strong or "knife-edge" assumptions are needed for the equilibrium to exist.
} 


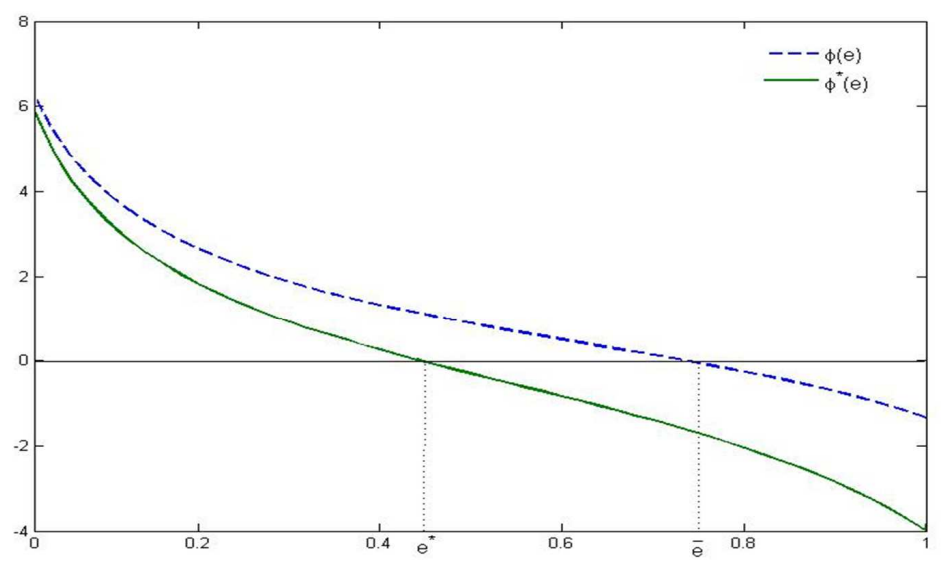

Figure 1: Illustration of $\phi^{*}(e)$ and $\phi(e)$ for $u(x)=\ln (x), w(e)=\sqrt{e}$ and $h(a)=\sqrt{a}$.

note that $(28)$ implies $\bar{a}^{\prime}(e)<0$, so that $\bar{e}>e^{*}$ directly implies $\bar{a}<a^{*}$. In words, the provision of aid will be too low, even though the period $t$ equilibrium induces the efficient tradeoff (given $e$ and thus $w$ ). Intuitively, a level of education that is "too high" causes the wage level to be "too large"; since the wage represents the (opportunity) cost of aid, the level of aid decreases.

\section{Conclusion}

We have studied intergenerational exchanges in an OLG framework with three generations. We have shown that Becker's rotten kids theorem holds for the single period game in the sense that informal aid is set according to an efficient rule. However, education spending is distorted upwards. The reason being that the old generation bears part of the education costs via higher bequests. In the stationary equilibrium the level of both transfers is inefficient. Education is too high and since higher education translates into higher opportunity costs of aid, the latter is too low.

\section{References}

[1] Becker, G.S., "A Theory of Social Interactions," Journal of Political Economy, 1974, 82 (6), 1063-1093. 
[2] Becker, G.S., "A Treatise on the Family," Harvard University Press, Cambridge, 1991.

[3] Bergstrom, T.C., 1989, "A Fresh Look at the Rotten Kids Theorem-and Other Household Mysteries," Journal of Political Economy, 97 (5), 1138-1159.

[4] Cremer, H., D. Kessler and P. Pestieau, "Intergenerational Transfers within the Family," European Economic Review, 1992, 36, 1-16.

[5] Cremer, H. and K. Roeder, "Long-Term Care and Lazy Rotten Kids," IZA Discussion Paper No. 7565, 2013.

[6] Glomm, G. , B. Ravikumar and I.C. Schiopu, "The Political Economy of Education Funding," in E.A. Hanushek, S. Machin and L. Woessmann, Eds., Handbook of The Economics of Education, 4, Amsterdam: Elsevier, 2011, 615-680.

[7] Oded, G., "Inequality, Human Capital Formation, and the Process of Development," in E.A. Hanushek, S. Machin and L. Woessmann, Eds., Handbook of The Economics of Education, 4, Amsterdam: Elsevier, 2011, 441-493.

[8] Rangel, A., "Forward and Backward Intergenerational Goods: Why Is Social Security Good for the Environment?," American Economic Review, 2003, 93 (3), 813-834.

[9] Veall, M.R., "Public Pensions as Optimal Social Contract," Journal of Public Economics, 1986, 31, 237-251. 